\title{
Aerosol-assisted CVD synthesis, characterisation and gas-sensing application of gold-functionalised tungsten oxide
}

\author{
F. Di Maggio ${ }^{1}$, M. Ling ${ }^{1}$, A. Tsang ${ }^{1}$, J. Covington ${ }^{2}$, J. Saffell ${ }^{3}$, and C. Blackman ${ }^{1}$ \\ ${ }^{1}$ Department of Chemistry, University College London, 20 Gordon Street, London WC1H 0AJ, UK \\ ${ }^{2}$ School of Engineering, University of Warwick, Coventry CV4 7AL, UK \\ ${ }^{3}$ Alphasense Ltd, 300 Avenue West, Skyline 120, Great Notley, Essex CM77 7AA, UK \\ Correspondence to: C. Blackman (c.blackman@ucl.ac.uk)
}

Received: 31 July 2014 - Revised: 13 October 2014 - Accepted: 24 October 2014 - Published: 3 December 2014

\begin{abstract}
Tungsten oxide nanoneedles (NNs) functionalised with gold nanoparticles (NPs) have been integrated with alumina gas-sensor platforms using a simple and effective co-deposition method via aerosol-assisted chemical vapour deposition (AACVD) utilising a novel gold precursor, $\left(\mathrm{NH}_{4}\right) \mathrm{AuCl}_{4}$. The gas-sensing results show that gold NP functionalisation of tungsten oxide NNs improves the sensitivity of response to ethanol, with sensitivity increasing and response time decreasing with increasing amount of gold.
\end{abstract}

\section{Introduction}

Tungsten oxide functionalised with gold nanoparticles (NPs) has found application in photocatalysis (Xi et al., 2012) and gas sensing (Vallejos et al., 2011; Annanouch et al., 2013), and recently Vallejos et al. (2011) demonstrated a surfactant- and polymer-free, single-step aerosol-assisted chemical vapour deposition (AACVD) method to synthesise thin films of tungsten oxide nanoneedles (NNs) decorated with gold NPs, which provides for direct integration of the nanomaterial with gas-sensing platforms (Vallejos et al., 2011). The observation that chemoresistive gas sensors fabricated from metal oxides functionalised with catalytic metal NPs show enhanced sensor response towards certain analytes has been explained using three mechanisms: spillover (enrichment of the surface of the metal oxide with analyte), Fermi level control (analyte changes the chemical state of the metal NPs leading to a large change in electronic interaction between oxide and metal) and the presence of oxidised states on the metal NPs forming an associated bulk effect and local/surface site on the oxide which interacts strongly with the analyte (Cuenya, 2010; Hübner et al., 2011). Only relatively small amounts of metal NPs need to be loaded on tungsten oxide NNs to show dramatically enhanced sensing properties (Vallejos et al., 2013), but the limit of the enhancement under variable loading is rarely reported. This paper reports on the successful fabrication of various loadings of gold NPs, utilising a novel gold AACVD precursor, $\left(\mathrm{NH}_{4}\right) \mathrm{AuCl}_{4}$, supported on tungsten oxide NNs, deposited directly on alumina gas-sensor substrates, and their gas-sensing properties with respect to ethanol and the correlation of sensitivity with gold loading.

\section{Experimental section}

Film deposition: gold NPs supported on tungsten oxide NNs were co-deposited at $375^{\circ} \mathrm{C}$ via AACVD of tungsten hexaphenoxide $\left(\mathrm{W}(\mathrm{OPh})_{6}\right)$ (Cross et al., 2003) and ammonium tetrachloroaurate(III) hydrate $\left(\mathrm{NH}_{4} \mathrm{AuCl}_{4} \cdot \mathrm{xH}_{2} \mathrm{O}\right)$ (Alfa Aesar, $99.9 \%)$ dissolved in acetone $\left(10 \mathrm{~cm}^{3}\right.$, Sigma-Aldrich, $\geq 99.6 \%)$ and methanol $\left(5 \mathrm{~cm}^{3}\right.$, Sigma-Aldrich, $\left.\geq 99.6 \%\right)$ (Table 1) using a custom-built reactor.

A Johnson Matthey Liquifog 2 operating at $1.6 \mathrm{MHz}$ was used to generate an aerosol from a solution containing both the tungsten and gold precursors, with the aerosol droplets transported to the heated substrate by a nitrogen (oxygenfree, BOC) gas flow. Annealing of the samples was carried out in air at $500^{\circ} \mathrm{C}$ for $2 \mathrm{~h}$. Alumina (A493 Kyocera) or gas-sensor platforms (as shown schematically in Fig. 1), on which both the heater and sensor are printed on the same 
Table 1. Details of samples.

\begin{tabular}{cccccc}
\hline & $\mathrm{W}(\mathrm{OPh})_{6}(\mathrm{~g})$ & $\mathrm{NH}_{4} \mathrm{AuCl}_{4}(\mathrm{~g})$ & Solvent (acetone : methanol 2:1) $\left(\mathrm{cm}^{3}\right)$ & Au at. \% & Temperature $\left({ }^{\circ} \mathrm{C}\right)$ \\
\hline Sample 1 & 0.10 & 0.010 & 15 & 4.5 & 375 \\
Sample 2 & 0.10 & 0.003 & 15 & 2.1 & 375 \\
Sample 3 & 0.10 & 0 & 15 & 0 & 375 \\
\hline
\end{tabular}

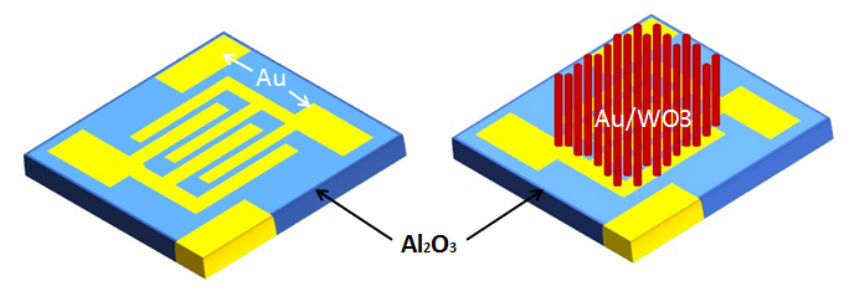

Figure 1. Schematic fabrication processes of the micro-sensor based on Au NPs supported on tungsten oxide NNs.

side of an alumina tile, were used as substrates. Both were cleaned with acetone and isopropyl alcohol prior to use.

Film analysis: the crystalline structures of samples were determined via X-ray diffraction (XRD) (Bruker, LinxEye D8-Discover, using $\mathrm{Cu} \mathrm{K} \alpha$ radiation operated at $40 \mathrm{kV}$ and $40 \mathrm{~mA}$ ) with glancing incident angle (tube at $1^{\circ}$ ), $0.05^{\circ}$ per step and $1 \mathrm{~s}$ per step, and $2 \theta$ from 10 to $66^{\circ}$. The microstructure of the films was examined with scanning electron microscopy (SEM) (Jeol 6310F, $5 \mathrm{kV}$ ) and high-resolution transmission electron microscopy (HR-TEM) (Jeol-2100, $200 \mathrm{kV}$ ), which was also used to obtain the information of lattice structure. The chemical composition measurement was determined via energy dispersive X-ray spectroscopy (EDX) $(20 \mathrm{kV})(\mathrm{Jeol} 6310 \mathrm{~F})$. Chemical and electronic states of the elements in the thin films were examined by means of X-ray photoelectron spectroscopy (XPS) (Thermo Scientific $\mathrm{K}-\mathrm{Alpha})$, using monochromatic $\mathrm{Al} \mathrm{K} \alpha$ radiation $(0.6 \mathrm{eV})$ and charge compensation by means of dual-beam charge neutralisation with an electron gun $(1 \mathrm{eV})$ and argon-ion gun $(\leq 10 \mathrm{eV})$, calibrated by the $\mathrm{C} 1 \mathrm{~s}$ peak at $284.7 \mathrm{eV}$. UV-Vis spectroscopy was performed using a double-monochromated Perkin Elmer Lambda 950 UV-Vis-NIR spectrophotometer in the 300 to $1100 \mathrm{~nm}$ range.

Gas-sensing tests: gas sensors were exposed to various concentrations of ethanol at $0.5,1,2,3$ and $4 \mathrm{ppm}$ respectively, at an operating temperature of $300^{\circ} \mathrm{C}$ and relative humidity of $50 \%$. The sensor response is defined as $R=$ $R_{\mathrm{a}} / R_{\mathrm{g}}$, where $R_{\mathrm{a}}$ is the resistance of the sensor in air and $R_{\mathrm{g}}$ is the resistance in ethanol. Sensors were exposed to ethanol vapours for $4 \mathrm{~min}$ and afterwards to air for $4 \mathrm{~min}$.

\section{Results and discussion}

Figure 2a shows pictures of Au-functionalised and nonfunctionalised tungsten oxide films deposited on alumina
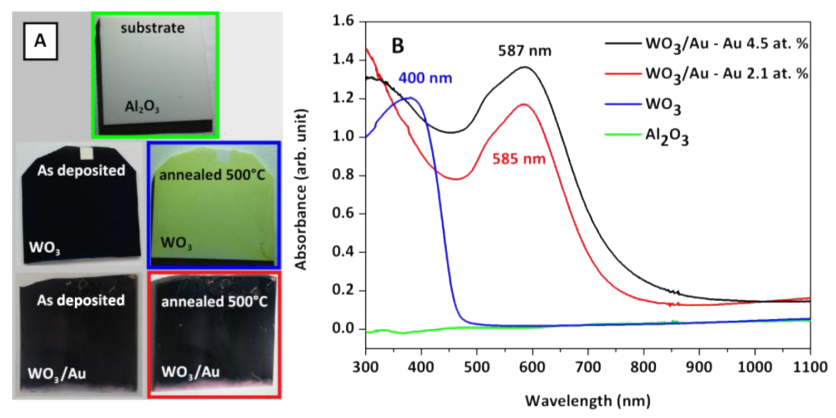

Figure 2. (a) Pictures of films deposited onto alumina substrate, before and after heating treatment at $500{ }^{\circ} \mathrm{C}$. (b) UV-Vis analyses of Au-functionalised $\mathrm{WO}_{3}$ (in black, 4.5 at. \%; red, 2.1 at. \%) and non-functionalised $\mathrm{WO}_{3}$ (in blue).

substrates before and after heat treatment in air at $500^{\circ} \mathrm{C}$. The pre-annealed films were characterised by a dark colour, as expected in the presence of partially reduced tungsten species, and after heating in air, non-functionalised tungsten oxide turned bright yellow, as expected for stoichiometric $\mathrm{WO}_{3}$, whilst Au-functionalised tungsten oxide was dark purple in colour, indicative of the presence of gold nanoparticles.

UV-Vis analyses (Fig. 2b) were performed collecting reflectance data $(R)$ and then converting into absorbance $(A)$ using the following formula (Viscarra Rossel et al., 2006):

$A=\log _{10}(1 / R)$,

analogous to absorbance units, $\log (1 / T)$, for transmission measurements.

For the non-functionalised tungsten oxide film, a peak is observed at $400 \mathrm{~nm}$, corresponding to the $\mathrm{WO}_{3}$ band edge ( $E_{\text {gap }} \mathrm{WO}_{3} \sim 2.7 \mathrm{eV}$ ). The Au-functionalised $\mathrm{WO}_{3}$ films show an additional absorbance at $585 \mathrm{~nm}$, corresponding to the surface plasmon resonance (SPR) peak of gold nanoparticles (El-Brolossy et al., 2008). Increasing the amount of gold precursor led to an increase in the absorbance of the gold plasmon resonance peak, suggesting a greater incorporation of gold particles.

XRD analysis (Fig. 3) of films deposited on Kyocera alumina substrates, after annealing, revealed the presence of monoclinic-phase $\mathrm{WO}_{3}(\mathrm{P} 21 / \mathrm{n}$ space group, $a=7.306 \AA$, $b=7.540 \AA, c=792 \AA$, and $\beta=90.88^{\circ}$; ICCD card no. 72 0677; Loopstra and Rietveld, 1969). Alumina peaks, exhibited in all patterns and depicted with dashed vertical lines, come from the alumina substrate. Both the $\mathrm{WO}_{3} / \mathrm{Au}$ and the 


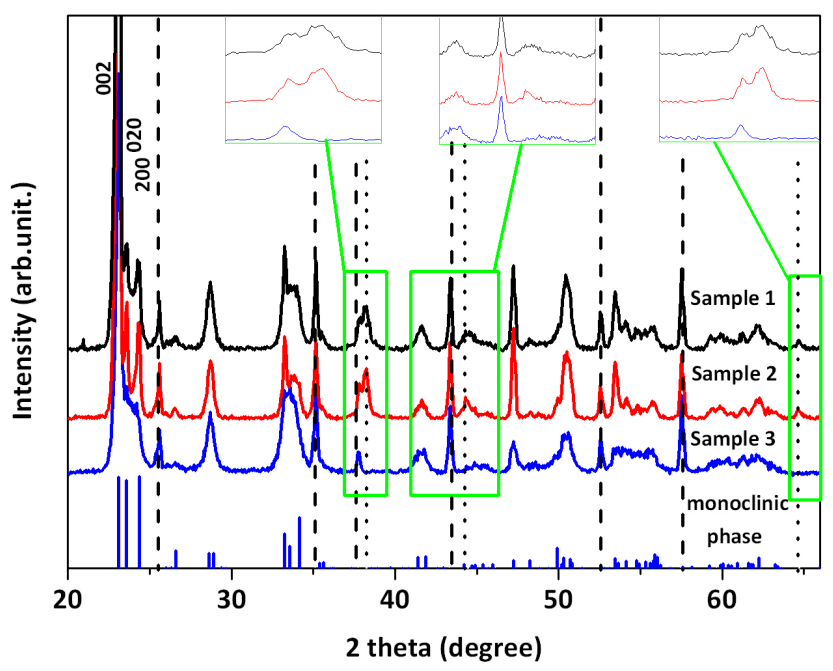

Figure 3. XRD patterns of Au-functionalised $\mathrm{WO}_{3}$ (in black, 4.5 at. \%; red 2.1 at. \%) and non-functionalised $\mathrm{WO}_{3}$ (in blue).

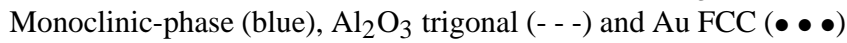
structures are also presented.

$\mathrm{WO}_{3}$ patterns showed preferred orientation in the [001] direction. In particular, the peak (002) at $23.11^{\circ} 2 \theta$ is very intense relative to the $(020)$ peak. Gold FCC peaks (dotted vertical lines) at $38.25^{\circ} 2 \theta, 44.30^{\circ} 2 \theta$ and $64.55^{\circ} 2 \theta$ were observed only in the $\mathrm{WO}_{3} / \mathrm{Au}$ pattern (zoomed patterns). This result confirms the co-deposition of tungsten oxide and gold metal. The mean grain size of Au nanoparticles was calculated to be about $26 \mathrm{~nm}$ based on the Scherrer formula:

$D=\frac{0.89 \lambda}{\beta \cos \theta}$,

where $D$ is the mean size of the crystalline domains, $\lambda$ is the $\mathrm{Cu} \mathrm{K} \alpha$ wavelength, $\beta$ is the line broadening at half the maximum intensity (FWHM) in radians and $\theta$ is half of the Bragg angle.

No shifts in the $\mathrm{WO}_{3}$ peaks position were observed, demonstrating that the monoclinic crystal structure of tungsten oxide was not changed after the addition of gold. Similar results for $\mathrm{WO}_{3}$ monoclinic phase were obtained by Vallejos et al. (2013) when using $\mathrm{HAuCl}_{4}$ as the gold precursor, but no Au peaks were observed in their XRD patterns, likely due to the lower amount of gold in the samples (0.09 Au at. \%).

Images from EDX analysis of the Au-functionalised and non-functionalised samples are shown in Table 2. The measured $\mathrm{Au}$ atomic percentage composition ( $\mathrm{Au}$ at. \% on $\mathrm{Au}-$ $\mathrm{WO}_{3}$ ) in the deposited films was 4.5 and 2.1 for sample 1 and sample 2 respectively, much lower than the theoretical values based on the composition of the precursor solution, which were 10.4 and 3.4 at. \% respectively. The incorporation efficiency was $44 \%$ for sample 1 and $63 \%$ for sample 2, much higher than the one determined by Vallejos et al. (2013), which had 5-10\% efficiency.

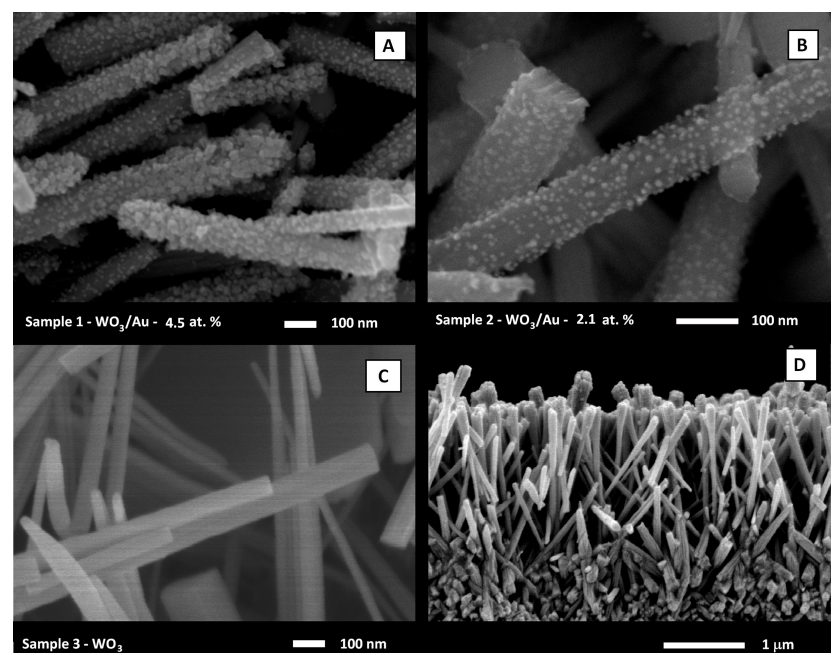

Figure 4. SEM images of (a) sample $1\left(\mathrm{WO}_{3} / \mathrm{Au} 4.5\right.$ at. \%), (b) sample $2\left(\mathrm{WO}_{3} / \mathrm{Au} 2.1\right.$ at. \%), (c) sample $3\left(\mathrm{WO}_{3}\right)$ and (d) cross section of sample 3 .

Table 2. Precursors theoretical and EDX experimental atomic percentage composition for gold element.

\begin{tabular}{lcc}
\hline & Theoretical Au at. \% & Experimental Au at. \% \\
\hline Sample 1 & 10.4 & 4.5 \\
Sample 2 & 3.4 & 2.1 \\
Sample 3 & 0 & 0 \\
\hline
\end{tabular}

SEM images are depicted in Fig. 4, clearly showing the increase in the amount of decorating nanoparticles on increasing the amount of gold precursor, with sample 1 (Fig. 4a) displaying a larger number of surface (gold) particles compared to sample 2 (Fig. 4b). No decorating particles were observed in the non-functionalised sample 3 (Fig. 4). The decorating particles were well dispersed all along the needles, demonstrating the good efficiency of the synthesis in terms of composition homogeneity. The thickness of the films, visible in a cross-section image in Fig. $4 \mathrm{~d}$, was roughly $1.5 \mu \mathrm{m}$ in all cases, and the tungsten oxide "needles" (ca. 0.1-0.2 $\mu \mathrm{m}$ diameter and ca. 1-2 $\mu \mathrm{m}$ length), although not perfectly vertically aligned, were predominantly perpendicular to the substrate.

HR-TEM was also used to characterise the crystalline habit of the nanoneedles and decorating nanoparticles (Fig. 5). The crystal planes in the long axis of the needles were separated by $0.378 \mathrm{~nm}$ (Fig. 5c), corresponding to the (020) plane of monoclinic $\mathrm{WO}_{3}$ monoclinic, and the decorating NP (Fig. 5d) exhibited planes separated by $0.23 \mathrm{~nm}$, consistent with (111) atomic planes of FCC gold. TEM examination showed that the gold nanoparticles were polydispersed both in shape (triangle, trapezoid, rod, sphere) and size (ca. 18 and $62 \mathrm{~nm}$ diameter), with an average size of $30 \mathrm{~nm}$. This result matches with the gold nanoparticles' grain 
Table 3. Au 4f and W 4f scans fitting parameters: peak, FWHM and area.

\begin{tabular}{lllcccccc}
\hline & & \multicolumn{4}{c}{ Peak 1 $\left(4 f_{5 / 2}\right)$} & \multicolumn{3}{c}{ Peak 2 $\left(4 f_{7 / 2}\right)$} \\
\cline { 3 - 9 } & & & Position & FWHM & Area & Position & FWHM & Area \\
\hline Sample 1 & Au 4.5 at. \% & W 4f & 37.84 & 1.098 & 51429 & 35.65 & 1.098 & 68586 \\
Sample 2 & Au 2.1 at. \% & W 4f & 37.79 & 1.115 & 52690 & 35.60 & 1.115 & 70267 \\
Sample 3 & Au 0 at. \% & W 4f & 37.84 & 1.165 & 86442 & 35.65 & 1.165 & 115284 \\
Sample 1 & Au 4.5 at. \% & Au 4f & 87.68 & 0.982 & 36077 & 83.90 & 0.982 & 48120 \\
Sample 2 & Au 2.1 at. \% & Au 4f & 87.68 & 0.997 & 37438 & 83.90 & 0.997 & 49935 \\
\hline
\end{tabular}
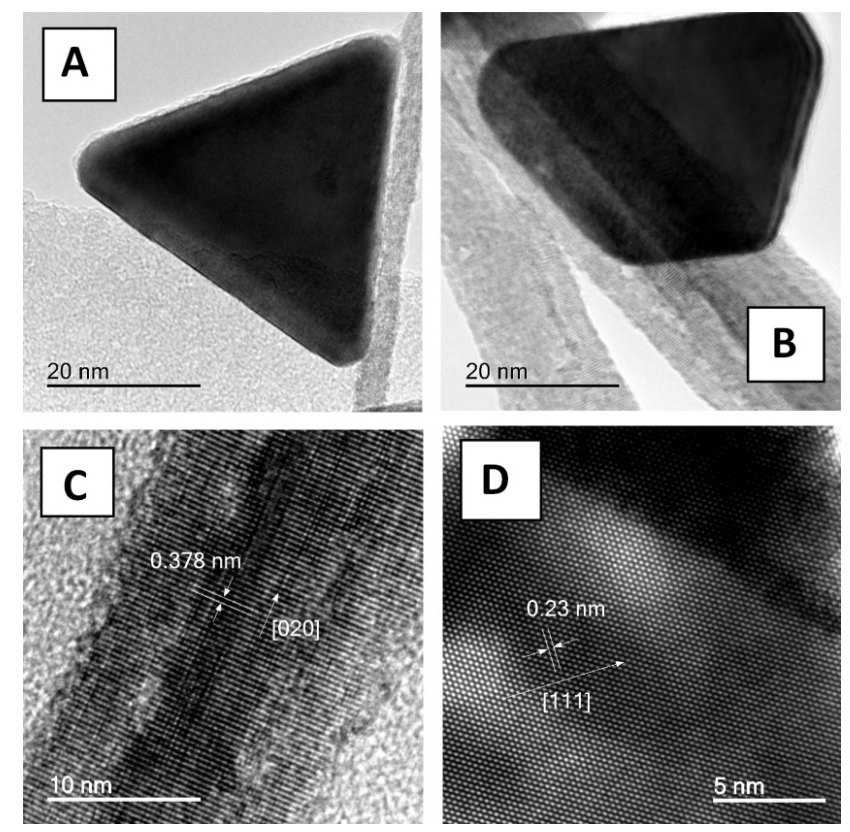

Figure 5. (a) and (b) TEM images of $\mathrm{WO}_{3} / \mathrm{Au}$ sample. HR-TEM for (c) $\mathrm{WO}_{3}$ nanoneedle and (d) gold nanoparticles.

size, $26 \mathrm{~nm}$, observed by using the Scherrer formula on the XRD pattern.

This is different to that observed previously using $\mathrm{HAuCl}_{4}$ as a gold precursor (Vallejos et al., 2013). In that case the gold NP displayed a spherical shape with a size between 4 and $11 \mathrm{~nm}$. This may be due to the different nature of the precursor or the different gold loading.

XPS high-resolution spectra for $\mathrm{WO}_{3}$ and $\mathrm{WO}_{3} / \mathrm{Au}$, after annealing, are shown in Fig. 6 and the relative fitting parameters are listed in Table 3.

The W 4f spectra in Fig. 6a show a single tungsten environment for all the samples, with the $4 \mathrm{f}_{7 / 2}$ peak centred at $35.6 \mathrm{eV}$, which corresponds to the $\mathrm{W}^{6+}$ oxidation state (Fleisch and Mains, 1982). The Au 4f peaks for the Au-functionalised $\mathrm{WO}_{3}$ samples were fitted using single Gaussian-Lorentzian functions and the $\mathrm{Au} 4 \mathrm{f}_{7 / 2}$ binding energy was found to be $83.9 \mathrm{eV}$ (Fig. 6b), corresponding to metallic gold (Dückers and Bonzel, 1989). Therefore W(VI)
Table 4. XPS Au atomic percentage composition. Oxygen : tungsten ratio.

\begin{tabular}{lccc}
\hline & Au at. \% EDX & Au at. \% XPS & O/W XPS \\
\hline Sample 1 & 4.5 & 9.5 & 2.7 \\
Sample 2 & 2.1 & 7.1 & 2.8 \\
Sample 3 & 0 & 0 & 2.8 \\
\hline
\end{tabular}

Table 5. Response time and recovery time variation to the different gold loadings.

\begin{tabular}{lcc}
\hline & Response time (s) & Recovery time (s) \\
\hline Sample 1 & 2.8 & 14.0 \\
Sample 2 & 5.3 & 9.1 \\
Sample 3 & 4.5 & 8.5 \\
\hline
\end{tabular}

and $\mathrm{Au}(0)$ were the only oxidation states found for these elements.

XPS analysis of annealed samples indicated a W/O ratio of 2.8 for samples 2 and 3 and a ratio of 2.7 for sample 1 (Table 4). This value is much higher compared to the 2.4 ratio obtained by Vallejos et al. (2013) in both $\mathrm{W}$ and $\mathrm{Au} / \mathrm{W}$ samples. The gold atomic percentage (Au at. \% on $\mathrm{Au}-\mathrm{WO}_{3}$ ) obtained via XPS (Table 4) is much higher than the one obtained via EDX (Table 2). This can be explained by taking into account the morphology of the $\mathrm{WO}_{3} / \mathrm{Au}$ system and the area analysed; SEM images (Fig. 4) show the Au nanoparticles are dispersed on the surface of the tungsten oxide nanoneedle, and therefore, with XPS being a surface analysis technique, the Au at. \% appears to be greater than EDX, which gives bulk information.

\section{Gas-sensing properties}

Gas-sensing properties of gold-functionalised and nonfunctionalised $\mathrm{WO}_{3}$ nanoneedles were tested towards ethanol vapours. Figure 7 shows the sensor response towards different amounts of analyte at an operating temperature of $300{ }^{\circ} \mathrm{C}$ in the presence of $50 \%$ of relative humidity. Gas sensors based on non-functionalised $\mathrm{WO}_{3}$ (sample 3 ) showed a very low response towards $0.5 \mathrm{ppm}$ of ethanol, with sensitiv- 

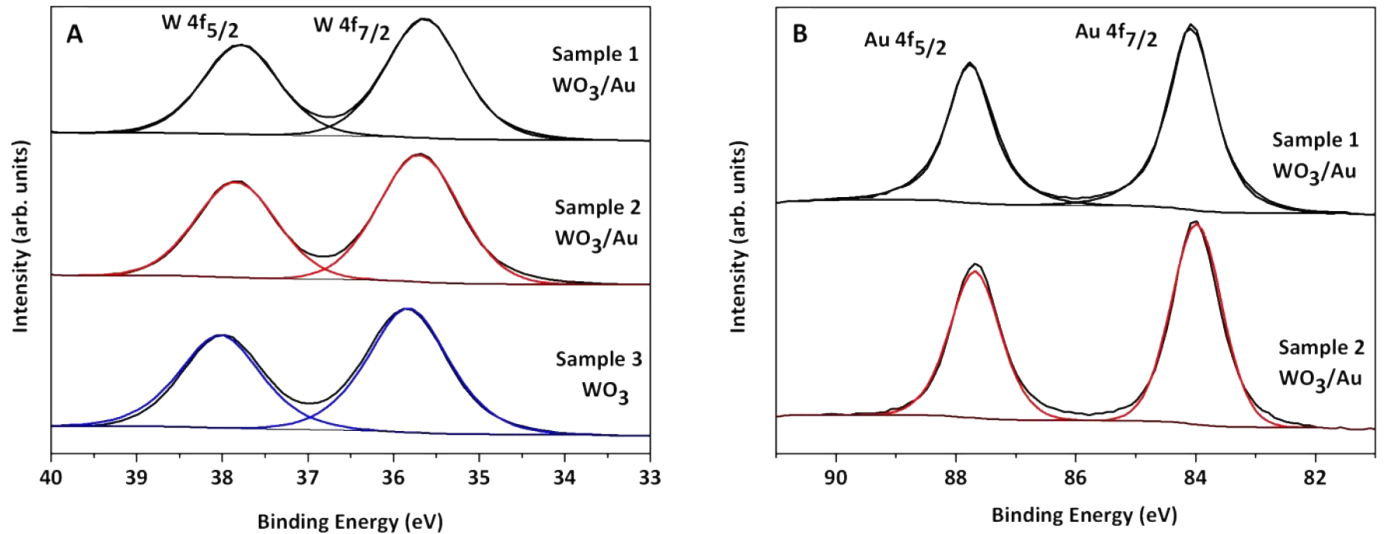

Figure 6. XPS spectra for sample $1\left(\mathrm{WO}_{3} / \mathrm{Au} 4.5\right.$ at. \%), sample $2\left(\mathrm{WO}_{3} / \mathrm{Au} 2.1\right.$ at. \%) and sample $3\left(\mathrm{WO}_{3}\right)$ films on alumina. (a) $\mathrm{W} 4 \mathrm{f}$ peaks and (b) $\mathrm{Au} 4 \mathrm{f}$, fitted with parameters in Table 3.

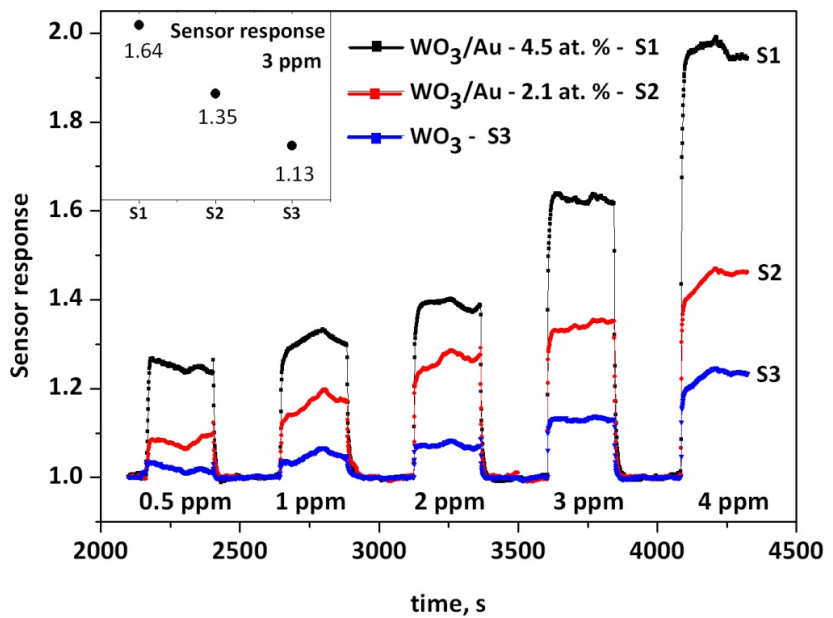

Figure 7. Gas-sensing response towards different amount of ethanol at $300^{\circ} \mathrm{C}$ as a function of increasing gold loading.

ity increasing in the presence of higher amounts of analyte as expected, up to a highest value of 1.2 when the concentration of ethanol was $4 \mathrm{ppm}$.

Sample 2 (Au 2.1 at. \%) and sample 1 (Au 4.5 at. \%) showed respectively 2 -fold and 5 -fold higher sensing response than non-functionalised gas sensors (sample 3), with increased response even towards low concentrations of analyte, close to 1.3 towards $0.5 \mathrm{ppm}$ of ethanol for sample 1 $(4.5 \% \mathrm{Au})$. These results demonstrate an enhancement in gas-sensing response by increasing the amount of gold loading. The highest loading amount used in this study was $4.5 \%$; however, as has been seen in catalysis studies (Epling and Hoflund, 1999), increasing the loading percentage does not necessarily lead to a linear improvement in catalytic performance. Therefore, further experiments will be conducted in order to determine the optimum loading of gold beyond which the activity is stable or decreases.
All sensors displayed an $n$-type response with decreasing resistance in the presence of the reducing gas (Fig. 7). The response and recovery times calculated for $3 \mathrm{ppm}$ ethanol (Table 5) exhibit approximately the same values for sample 2 $(2.1 \% \mathrm{Au})$ and 3 (non-functionalised), a response time of $5 \mathrm{~s}$ and recovery time of $9 \mathrm{~s}$. Sample $1(4.5 \% \mathrm{Au})$ had the fastest response time, $2.8 \mathrm{~s}$, but the slowest recovery time, $14 \mathrm{~s}$.

\section{Conclusions}

Tungsten oxide NNs functionalised with Au NPs integrated have been synthesised via AACVD using a single-step method and integrated onto alumina gas-sensing platforms to produce gas sensors. The average of Au NPs diameter is $30 \mathrm{~nm}$ on the tungsten oxide NNs (ca. $0.1-0.2 \mu \mathrm{m}$ diameter and ca. 1-2 $\mu \mathrm{m}$ length). An increase in the amount of Au precursor $\left(\mathrm{NH}_{4} \mathrm{AuCl}_{4}\right)$ in the initial solution produced a higher loading of Au NPs on the tungsten oxide NNs. Gas-sensing tests towards ethanol vapours showed an increase in sensor response in samples with higher amounts of gold nanoparticles, with increases in response towards $3 \mathrm{ppm}$ of ethanol of 2 -fold and 5-fold over non-functionalised $\mathrm{WO}_{3}$ as the gold loading was raised from 2.1 to $4.5 \%$ respectively. 
Acknowledgements. This work was supported by UCL through its Impact Studentship Programme.

Edited by: A. Lloyd Spetz

Reviewed by: two anonymous referees

\section{References}

Annanouch, F. E., Vallejos, S., Stoycheva, T., Blackman, C., and Llobet, E.: Aerosol assisted chemical vapour deposition of gassensitive nanomaterials, Thin Solid Films, 548, 703-709, 2013.

Cross, W. B., Parkin, I. P., O’Neill, S. A., Williams, P. A., Mahon, M. F., and Molloy, K. C.: Tungsten oxide coatings from the aerosol-assisted chemical vapor deposition of W (OAr) 6 $(\mathrm{Ar}=\mathrm{C} 6 \mathrm{H} 5, \mathrm{C} 6 \mathrm{H} 4 \mathrm{~F}-4, \mathrm{C} 6 \mathrm{H} 3 \mathrm{~F} 2-3,4)$; photocatalytically active $\gamma-\mathrm{WO}_{3}$ films, Chem. Mater., 15, 2786-2796, 2003.

Cuenya, B. R.: Synthesis and catalytic properties of metal nanoparticles: Size, shape, support, composition, and oxidation state effects, Thin Solid Films, 518, 3127-3150, 2010.

Dückers, K. and Bonzel, H. P.: Core and valence level spectroscopy with $\mathrm{Y} \mathrm{M} \zeta$ radiation: $\mathrm{CO}$ and $\mathrm{K}$ on (110) surfaces of Ir, Pt and Au, Surf. Sci., 213, 25-48, 1989.

El-Brolossy, T. A., Abdallah, T., Mohamed, M. B., Abdallah, S., Easawi, K., Negm, S., and Talaat, H.: Shape and size dependence of the surface plasmon resonance of gold nanoparticles studied by Photoacoustic technique, Eur. Phys. J.-Spec. Top., 153, 361364, 2008.

Epling, W. S. and Hoflund G. B.: Catalytic oxidation of methane over ZrO2-supported Pd catalysts, J. Catal., 182, 5-12, 1999.
Fleisch, T. H. and Mains, G. J.: An XPS study of the UV reduction and photochromism of $\mathrm{MoO} 3$ and $\mathrm{WO}_{3}$, J. Chem. Phys., 76, 780-786, 1982.

Hübner, M., Koziej, D., Bauer, M., Barsan, N., Kvashnina, K., Rossell, M. D., Weimar, U., and Grunwaldt, J. D.: The Structure and Behavior of Platinum in SnO2-Based Sensors under Working Conditions, Angew. Chem. Int. Edit., 50, 2841-2844, 2011.

Loopstra, B. O. and Rietveld, H. M.: Further refinement of the structure of $\mathrm{WO}_{3}$, Acta Crystallogr. B, 25, 1420-1421, 1969.

Vallejos, S., Stoycheva, T., Umek, P., Navio, C., Snyders, R., Bittencourt, C., Llobet, E., Blackman, C., Moniz, S., and Correig, $\mathrm{X}$.: Au nanoparticle-functionalised $\mathrm{WO}_{3}$ nanoneedles and their application in high sensitivity gas sensor devices, Chem. Commun., 47, 565-567, 2011.

Vallejos, S., Umek, P., Stoycheva, T., Annanouch, F., Llobet, E., Correig, X., De Marco, P., Bittencourt, C., and Blackman, C.: Single-Step Deposition of Au-and Pt-NanoparticleFunctionalized Tungsten Oxide Nanoneedles Synthesized Via Aerosol-Assisted CVD, and Used for Fabrication of Selective Gas Microsensor Arrays, Adv. Funct. Mater., 23, 1313-1322, 2013.

Viscarra Rossel, R. A., McGlynn, R. N., and McBratney, A. B.: Determining the composition of mineral-organic mixes using UVvis-NIR diffuse reflectance spectroscopy, Geoderma, 137, 7082, 2006.

Xi, G., Ye, J., Ma, Q., Su, N., Bai, H., and Wang, C.: In situ growth of metal particles on 3D urchin-like $\mathrm{WO}_{3}$ nanostructures, J. Am. Chem. Soc., 134, 6508-6511, 2012. 